\title{
PERILAKU CARING PERAWAT DENGAN KEPUASAN PASIEN
}

\author{
Edgar Ch. Q. Wuwung ${ }^{1}$, Lenny Gannika ${ }^{1}$, Michael Karundeng²
}

1. Program Studi Ilmu Keperawatan Fakultas Kedokteran Universitas Sam Ratulangi

2. Dinas Kesehatan Kota Manado

Email: equeniawan@gmail.com

\begin{abstract}
Background Nursing Services is a holistic service that encompasses Bio, Psycho, Socio and Spirituality which contains Caring attitude. Patient satisfaction can be influenced by several factors one of them is caring attitude of nurses. The Purpose of this study is to identify relationship between Nurse's Caring and Patient Satisfaction at Hospital GMIM Pancaran Kasih Manado. Method of this study used cross sectional study design. Sample of this study consist of 90 respondents taken by random sampling method and data collection method used nurses caring and patient satisfaction questionnaire. Chi-square was used to analyze the data. the Results of this study showed out of 90 respondents, most of them were Satisfied (60\%) and said that the Nurse have Caring attitude (58,9\%) with p-value 0.04 smaller than 0.05. Conclusion of this study stated there was a relationship between Nurse's Caring and Patient Satisfaction at Rumah Sakit Umum GMIM Pancaran Kasih Manado. Suggestions from this study are nurses expected should maintain the quality of Nursing Care so that patient satisfaction can be maintained.
\end{abstract}

Keywords: Nurse's Caring, Patient Satisfaction, Nurse, Nursing Management.

Abstrak: Latar Belakang Pelayanan Keperawatan merupakan suatu pelayanan yang holistik yang melingkupi Bio, Psiko, Sosio dan Spiritual yang didalamnya terkandung sikap Caring. Kepuasan pasien dapat dipengaruhi oleh beberapa faktor salah satunya adalah sikap caring perawat. Tujuan studi ini untuk mengetahui hubungan antara perilaku Caring Perawat dengan Kepuasan Pasien di Rumah Sakit Umum GMIM Pancaran Kasih Manado. Metode studi ini menggunakan desain penelitian cross-sectional. Sampel studi ini berjumlah 90 responden dengan metode pengambilan sampel random sampling dan untuk mengumpulkan data menggunakan kuesioner perilaku caring perawat dan kepuasan pasien. Uji chi-square untuk melakukan analisa data hubungan kedua variabel Hasil dari penelitian ini, didapatkan dari 90 Responden yang diteliti sebagian besar Mengatakan puas $(60 \%)$ dan berpendapat bahwa perawat memiliki perilaku Caring $(58,9 \%)$ dengan $p$-value 0.04 lebih kecil dari 0.05. Kesimpulan dari penelitian ini bahwa terdapat hubungan antara Perilaku Caring Perawat dan Kepuasan Pasien di Rumah Sakit Umum GMIM Pancaran Kasih Manado. Saran dari penelitian ini diharapkan perawat agar mempertahankan kualitas Asuhan Keperawatan agar kepuasan pasien dapat tetap terjaga.

Kata Kunci : Perilaku Caring, Kepuasan Pasien, Perawat, Keperawatan Manajemen. 


\section{PENDAHULUAN}

Keperawatan didefinisikan sebagai ilmu pengetahuan dan suatu seni yang terfokuskan pada promosi kualitas hidup yang didefinisikan oleh orang atau keluarga, melalui seluruh pengalaman hidupnya dari kelahiran sampai asuhan pada kematian.

Di Indonesia juga menunjukan bahwa banyak Perawat yang berperilaku Caring, yaitu hasil studi di pulau jawa di kota Jakarta menunjukan sebanyak $64,2 \%$ dari 81 orang Perawat (Kalsum, 2016). Penelitian lainnya dipulau Jawa yaitu kota Semarang menunjukan hasil sebanyak $60 \%$ dari 50 Perawat Berperilaku Caring (Suweko \& Warsito, 2019).

Untuk di pulau Sulawesi juga telah dilakukan oleh Abdul, (2013) memukan hasil bahwa sebanyak 81,3\% dari 157 Perawat Berperilaku Caring di Rumah Sakit Umum Daerah Kota Baubau. Kemudian penelitian yang dilakukan di dipulau Sulawesi khususnya Manado, telah dilaksanakan di ruangan Perawatan anak, Wanita Dewasa dan Pria Dewasa Rumah Sakit Uumum GMIM Pancaran Kasih Manado dan hasil yang didapatkan sebanyak 56,4\% Perawat Berperilaku Caring (Paputungan, 2018).

Peneliti telah melakukan studi pendahuluan pada pasien yang dirawat di paviliun Hana Rumah Sakit Umum GMIM Pancaran Kasih Manado tanggal 25 Maret 2019 dengan 10 sampel penelitian. Dalam survei awal ini peneliti melakukan wawancara dengan lembaran kuesioner kepada 10 orang responden perempuan dengan pertanyaan terkait kepuasan pasien terhadap perilaku caring Perawat di paviliun tersebut.

Beradasarkan uraian diatas maka peneliti tertarik melakukan penelitian tentang "Hubungan perilaku caring Perawat dengan kepuasan pasien di paviliun Hana Rumah Sakit Umum GMIM Pancaran Kasih Manado" tahun 2019.

\section{METODE PENELITIAN}

Jenis penelitian yang digunakan adalah penelitian survey analitik dengan menggunakan desain cross sectional Penelitian ini telah di laksanakan di Paviliun Hana RSU GMIM Pancaran Kasih Manado pada bulan Agustus 2019.

Populasi pada penelitian ini adalah rata-rata jumlah pasien yang dirawat di paviliun Hana Rumah Sakit Umum Gmim Pancaran Kasih Manado selama 3 bulan terakhir sebanyak 113 orang pasien. Besaran sampel ditentukan dengan rumus Slovin sehingga berdasarkan perhitungan rumus slovin, besar sampel yang digunakan dalam penelitian ini yaitu sebanyak 89 pasien di Paviliun Hana namun digenapkan menjadi 90 sampel.

Instrumen yang akan digunakan dalam penelitian ini berupa daftar pernyataan kuesioner Perilaku Caring dan kuesioner kepuasan pasien yang akan dibagikan kepada pasien yang memenuhi kriteria inklusi, kuesioner perilaku Caring dan kepuasan pasien akan menggunakan kuesioner yang telah teruji reabilitas dan validitasnya. 
HASIL PENELITIAN

Responden dalam penelitian ini adalah pasien yang menjadi sampel, yang terjangkau selama penelitian yaitu sebanyak 90 orang pasien dengan karakterisitik sebagai berikut:

Tabel 5.1. Distribusi sampel menurut jenis kelamin.

\begin{tabular}{lll}
\hline Jenis Kelamin & f & \% \\
\hline Perempuan & 90 & 100 \\
Laki-Laki & 0 & 0 \\
\hline Total & $\mathbf{9 0}$ & $\mathbf{1 0 0 , 0}$ \\
\hline & Sumber : Data Primer 2019
\end{tabular}

Tabel 5.2 Distribusi sampel menurut usia

\begin{tabular}{lll}
\hline Usia & $\mathbf{f}$ & $\mathbf{\%}$ \\
\hline 17-25 tahun & 8 & 8,9 \\
26-35 tahun & 25 & 27,8 \\
36-45 tahun & 29 & 32,2 \\
46-55 Tahun & 20 & 22,2 \\
56-65 Tahun & 5 & 5,6 \\
65 Tahun keatas & 3 & 3.3 \\
\hline Total & $\mathbf{9 0}$ & $\mathbf{1 0 0 , 0}$ \\
\hline
\end{tabular}

Sumber : Data Primer 2019

Berdasarkan data diatas menunjukkan kelompok usia 36-45 tahun berjumlah 29 bahwa Responden Sebagian besar dari Orang.

Tabel 5.3 Distribusi sampel menurut pekerjaan

\begin{tabular}{lll}
\hline Pekerjaan & f & \% \\
\hline Aparat Sipil Negara & 26 & 28,9 \\
Wirasasta (Lainnya) & 49 & 54,4 \\
Pegawai Swasta & 15 & 16,7 \\
\hline Total & $\mathbf{9 0}$ & $\mathbf{1 0 0 , 0}$ \\
\hline
\end{tabular}

Sumber : Data Primer 2019

Berdasarkan data diatas menunjukkan bekerja sebagai Wiraswasta (Lainnya), bahwa sebagian besar Responden yang berjumlah 46 Orang.

Tabel 5.4 Distribusi sampel menurut pendidikan

\begin{tabular}{lcc}
\hline Pendidikan & f & \% \\
\hline S1 & 39 & 43,3 \\
SD & 4 & 4,4 \\
SMP & 19 & 21,1 \\
SMA & 28 & 31,1 \\
\hline Total & $\mathbf{9 0}$ & $\mathbf{1 0 0 , 0}$ \\
\hline
\end{tabular}

Berdasarkan data diatas menunjukkan pendidikan sampai SMA sebanyak $38 \%$. bahwa sebagian besar responden memiliki 
Tabel 5.1 Distribusi responden berdasarkan Perilaku Caring Perawat dan Kepuasan Pasien

\begin{tabular}{lccccc}
\hline Variabel & $\mathbf{f}$ & $\boldsymbol{\%}$ & $\begin{array}{c}\text { Kepuasan } \\
\text { Pasien }\end{array}$ & $\mathbf{f}$ & $\%$ \\
\hline $\begin{array}{l}\text { Perilaku } \\
\text { Caring } \\
\text { perawat } \\
\text { Caring }\end{array}$ & 53 & 58,9 & Puas & 54 & 60 \\
\hline $\begin{array}{l}\text { Kurang } \\
\text { Caring }\end{array}$ & 37 & 41,1 & $\begin{array}{c}\text { Kurang } \\
\text { Puas }\end{array}$ & 36 & 40 \\
\hline Total & 90 & 100 & & 90 & 100 \\
\hline
\end{tabular}

Sumber : Data Sekunder, 2019

Berdasarkan data diatas menunjukan bahwa responden mengaku perawat caring sebanyak 58,9\%, dang mengaku puas sebanyak $54 \%$.

Tabel 5.3 Hubungan Perilaku Caring Perawat Berhubungan dengan Kepuasan Pasien di Paviliun Hana Rumah Sakit Umum GMIM Pancaran Kasih Manado

\begin{tabular}{|c|c|c|c|c|c|c|c|}
\hline \multirow{3}{*}{$\begin{array}{c}\text { Perilaku Caring } \\
\text { Perawat }\end{array}$} & \multicolumn{4}{|c|}{ Tingkat Kepuasan Pasien } & \multicolumn{2}{|c|}{ Total } & $\begin{array}{c}p- \\
\text { value }\end{array}$ \\
\hline & \multicolumn{2}{|c|}{ Puas } & & $\begin{array}{l}\text { Tidak } \\
\text { Puas }\end{array}$ & \multirow{2}{*}{$\mathbf{f}$} & \multirow{2}{*}{$\%$} & \multirow{5}{*}{0,04} \\
\hline & f & $\%$ & $\mathbf{f}$ & $\%$ & & & \\
\hline Caring & 37 & 41.1 & 16 & 17,8 & 53 & 58,9 & \\
\hline Kurang Caring & 17 & 18,9 & 20 & 22,2 & 37 & 41,1 & \\
\hline Total & 54 & 60 & 36 & 40 & 90 & 100 & \\
\hline
\end{tabular}

Sumber : Data Primer, 2019

Berdasarkan data diatas jumlah. Hasil uji hipotesa dengan menggunakan uji $C h i$ Square dengan tingkat kepercayaan $95 \%(\alpha$ $0,05)$, menunjukan adanya hubungan antara

\section{PEMBAHASAN}

\section{Analisa Univariat}

\section{Karakterisktik Responden}

Hasil penelitian menunjukkan bahwa semua sampel memiliki jenis kelamin Perempuan. Hasil penelitian menunjukkan bahwa responden sebagian besar dari kelompok usia 36-45 tahun sebanyak 29 orang kemudian diikuti oleh kelompok usia 26-35 tahun 25 Orang, 46-55 tahun sebanyak 20 orang, 17-25 tahun sebanyak 8 orang, 56-65 Tahun Orang dan yang paling sedikit berasal dari kelompok usia 65 Tahun keatas yaitu sebanyak 2 Orang. Hasil penelitian mennunjukan bahwa sebagian besar responden memiliki pekerjaan Aparat perilaku Caring Perawat dan Kepuasan Pasien dimana nilai $p$-value $=0,04$ lebih kecil dari $\alpha=0,05$.

Sipil Negara sebanyak 27 Orang, pegawai Swasta sebanyak 17 Orang dan yang paling banyak adalah Wiraswasta (Lainnya) yaitu sebanyak 46 Orang.

Hasil penelitian menunjukkan bahwa Responden yang memiliki pendidikan S1 adalah sebanyak 39 orang, SMP 16 orang, SMA 31 orang dan yang paling sedikit adalah SD sebanyak 4 Orang.

\section{Perilaku Caring Perawat}

Hasil penelitian menunjukan bahwa dari 90 responden didapati perawat Caring, yaitu sebesar 53 Orang sedangkan 17 Orang diantaranya mengatakan Perawat kurang Caring. Hasil penelitian ini juga 
menemukan bahwa perilaku Caring Perawat di Paviliun Hana Rumah Sakit Umum GMIM Pancaran Kasih Manado sebagian besar Caring karena Perawat mengetahui dan mengenal dengan tepat keluarga pasien, bersikap bersahabat, memperhatikan keluhan keluarga dari pasien yang sedang dirasakan, memiliki rasa empati, membantu memenuhi kebutuhan pasien sesuai dengan kemampuan atau ketidakmampuan pasien dan tetunya selalu sabar merawat pasien. Hasil penelitian ini juga sesuai dengan beberapa penelitian mengenai Perilaku Caring, dalam studi yang dilakukan dibeberapa daerah di Indonesia juga menunjukan bahwa banyak Perawat yang berperilaku Caring, yaitu hasil studi di pulau jawa di kota Jakarta menunjukan sebanyak 64,2\% dari 81 orang Perawat (Kalsum, 2016). Penelitian oleh Abdul, (2013) memukan hasil bahwa sebanyak $81,3 \%$ dari 157 Perawat Berperilaku Caring di Rumah Sakit Umum Daerah Kota Baubau.

Akan tetapi berdasarkan hasil studi, ditemukan juga beberapa responden yang mengatakan Perawat Paviliun Hana Rumah Sakit Umum GMIM Pancaran Kasih Manado Berperilaku Kurang Caring. Peneliti berasumsi bahwa hal ini dapat terjadi dikarenakan beberapa Perawat kurang mengetahui dan mengenal dengan tepat keluarga pasien, kurang bersikap bersahabat, kurang memperhatikan keluhan keluarga dari pasien yang sedang dirasakan, dan kurang memiliki rasa empati.

Kesimpulan dari hasil penelitian ini bahwa sebagian besar responden mengatakan profesi Perawat Paviliun Hana Rumah Sakit Umum GMIM Pancaran Kasih Manado berperilaku Caring dikarenakan sikap Perawat itu sendiri seperti mengenal dengan tepat keluarga pasien, bersikap bersahabat, memperhatikan keluhan keluarga dari pasien yang sedang dirasakan, memiliki rasa empati, membantu memenuhi kebutuhan pasien sesuai dengan kemampuan atau ketidakmampuan pasien dan tetunya selalu sabar merawat pasien.

\section{Kepuasan Pasien}

Hasil penelitian menunjukan bahwa sebagian besar responden puas dengan pelayanan Keperawatan Paviliun Hana Rumah Sakit GMIM Pancaran Kasih Manado Sebanyak 54 Orang mengatakan puas, dan yang kurang puas sebanyak 36 Orang. Responden merasa puas dengan pelayanan Keperawatan karena Perawat bertindak cepat dalam melayani pasien setiap saat, melaporkan segala detail perubahan pasien kepada dokter sewaktu melakukan kunjungan, memperhatikan keluhan keluarga pasien, selalu menanyakan keluhan Pasien dan tentunya selalu sabar dalam memberikan pelayanan.

Hasil penelitian ini sesuai dengan hasil studi oleh Suweko, (2019), dalam studi tersebut dikatakan bahwa tingkat Kepuasan pasien terjadi karena kinerja Perawat dalam memberikan suatu pelayanan, lebih dari apa yang diharapkannya sehingga pasien merasa sangat puas saat menerima pelayanan. Studi oleh Mailani, (2017), juga menemukan hal yang sama pasien merasa tidak puas apabila perilaku Caring yang diberikan oleh Perawat sangat kurang dan akan membuat kualitas jasa dalam hal ini Rumah Sakit ikut menurun.

Akan tetapi berdasarkan hasil penelitian, ditemukan juga beberapa responden yang mengatakan tidak puas dengan pelayanan Keperawatan Paviliun Hana Rumah Sakit Umum GMIM Pancaran Kasih Manado. Hal ini terjadi dikarenakan beberapa beberapa responden merasa Ruang rawat inap kurang nyaman, kurang rapi dan bersih, Perawat kurang bersikap ramah dan sopan dan Perawat kurang meluangkan waktu khusus untuk berkomunikasi dengan pasien, hal ini sejalan dengan teori yang dikemukakan oleh Abdul (2013), bahwa Kepuasan pasien dapat bersumber dari banyak faktor seperti kurangnya fasilitas yang memadai, atau bahkan dari pelayanan Keperawatan itu sendiri yang memang kurang memuaskan. 
Sehingga membuat klien merasa penyedia layanan kurang mampu Memahami kebutuhan dan keinginan konsumen sehingga dapat memberikan penilaian yang kurang baik kepada Pelayanan Keperawat maupun Rumah Sakit itu sendiri.

Kesimpulan dari hasil ini bahwa kepuasan terjadi dikarenakan Perawat melakukan pelayanan yang sangat holistik meliputi bio psiko sosial dan spiritual, Perawat Paviliun Hana Rumah Sakit Umum GMIM Pancaran Kasih Manado juga lebih mengenal dengan tepat keluarga pasien, bersikap bersahabat, memperhatikan keluhan keluarga dari pasien yang sedang dirasakan, memiliki rasa empati, membantu memenuhi kebutuhan pasien sesuai dengan kemampuan atau ketidakmampuan pasien.

\section{Analisa Bivariat}

\section{Hubungan Perilaku Caring Perawat Dengan Kepuasan Pasien di Paviliun Hana Rumah Sakit Umum GMIM Pancaran Kasih Manado}

Hasil analisis uji hipotesis chisquare dengan tingkat kepercayaan 95\% ( $\alpha$ $0,05)$, menunjukan adanya hubungan yang signifikan antara Caring perawat dan kepuasan pasien dimana nilai $p$-value $=$ 0,004 lebih kecil dari $\alpha=0,05$. Dengan demikian terdapat hubungan antara Perilaku Caring Perawat dengan Kepuasan Pasien dimana semakin Caring seorang perawat maka kepuasan pasien akan semakin puas Pasien Paviliun Hana Rumah Sakit Umum GMIM Pancaran Kasih.

Hasil studi ini sesuai dengan yang dilakukan oleh Kalsum (2016), di kota Jakarta yang menunjukkan bahwa Perilaku Caring seorang Perawat memiliki hubungan yang signifikan dengan kepuasan pasien, semakin Caring seorang Perawat maka akan semakin puas seorang pasien yang mendapatkan pelayanan keperawatan. Kemudian untuk Studi yang dilakukan di Kota Bau Bau dilakukan oleh Abdul (2013), ia juga mendapati hal yang sama dimana terdapat hubungan yang sangat signifikan antara Perilaku Caring dan Kepuasan seorang pasien dalam studinya ia menemukan bahwa Kepuasan pasien dapat disebabkan oleh beberapa faktor namun faktor yang paling besar ialah Caring dari Perawat itu sendiri. Namun hasil studi ini berbeda dengan hasil studi oleh Azizah (2013) ia menemukan bahwa hanya beberapa faktor saja yang memiiki hubungan dengan kepuasan pasien sedangkan Perilaku Caring Perawat tidak.

Hasil penelitian pada studi ini dapat dilihat pada tabel 5.3, menunjukan terdapat 37 orang responden yang merasa perilaku pelayanan Keperawatan di Paviliun Hana Rumah Sakit GMIM Pancaran Kasih Manado sudah Caring karena Perawat bertindak cepat dalam melayani pasien setiap saat, melaporkan segala detail perubahan pasien kepada dokter sewaktu melakukan kunjungan, memperhatikan keluhan keluarga pasien, selalu menanyakan keluhan Pasien dan tentunya selalu sabar dalam memberikan pelayanan dan mengatakan puas dengan pelayanan Keperawatan, sedangkan sekitar 16 orang responden mengatakan pelayanan Keperawatan di Paviliun Hana sudah Caring namun masih merasa kurang puas dengan itu.

Hasil penelitian yang dapat dilihat pada tabel 5.3 juga menunjukan bahwa terdapat 20 responden yang mengatakan bahwa Perawat kurang Caring karena tidak mencerminkan sikap seperti bertindak cepat dalam melayani pasien setiap saat, melaporkan segala detail perubahan pasien kepada dokter sewaktu melakukan kunjungan, memperhatikan keluhan keluarga pasien, selalu menanyakan keluhan Pasien dan tidak sabar dalam memberikan pelayanan dan mereka mengatakan tidak puas. Hasil ini sejalan dengan hasil penelitian oleh Mailani (2017), di Padang ia juga menemukan bahwa pelayanan Caring yang buruk tentunya sudah sangat mutlak membuat seorang pasien merasa tidak puas karena merasa tidak nyaman dan memperburuk keadaanya.

Selain itu juga Hasil penelitian yang dapat dilihat pada tabel 5.3 pada studi ini juga ditemukan sekitar 16 orang responden 
mengatakan pelayanan Keperawatan di Paviliun Hana sudah Caring namun masih merasa kurang puas dengan itu karena Perawat bertindak cepat dalam melayani pasien setiap saat, melaporkan segala detail perubahan pasien kepada dokter sewaktu melakukan kunjungan, memperhatikan keluhan keluarga pasien, selalu menanyakan keluhan Pasien dan tentunya selalu sabar dalam memberikan pelayanan namun masih merasa tidak puas dengan hal itu. Hal ini sejalan dengan hasil penelitian oleh Abdul (2013), yang mana hal tersebut dapat terjadi oleh beberapa faktor seperti pasien berasal dari golongan pekerjaan tertentu yang memiliki keinginan lebih dan lebih lagi dalam mendapatkan perlakuan khusus dikarenakan mereka terbiasa di lingkungan pekerjaan yang perfeksionis sedangkan seorang Perawat tidak hanya merawat satu orang saja. Selain itu dalam penelitian ini juga didapati 17 Responden mengatakan Perilaku Perawat kurang caring namun merasa puas dengan pelayanan Keperawatan. Hal ini sesuai dengan hasil penelitian oleh Abdul (2013) bahwa, sebagian masyarakat tidak terlalu memperdulikan dengan perilaku seorang Perawat mereka berfikir yang terpenting mereka sembuh dan dapat keluar dari Rumah Sakit.

Kesimpulan dari penelitian ini bahwa terdapat hubungan dengan kepuasan pasien dikarenakan Perawat di Pavilion Hana Rumah Sakit Umum GMIM Pancaran Kasih Manado memiliki perilaku caring yang baik, seperti melakukan bertindak cepat dalam melayani pasien setiap saat, melaporkan segala detail perubahan pasien kepada dokter sewaktu melakukan kunjungan, memperhatikan keluhan keluarga pasien, selalu menanyakan keluhan Pasien dan tentunya selalu sabar dalam memberikan pelayanan. Dari perilaku Caring seperti inilah yang membuat pasien merasa dan mengatakan puas dengan pelayanan Keperawatan.

\section{KESIMPULAN}

Terdapat hubungan antara Perilaku Caring Perawat dengan Kepuasan Pasien di Paviliun Hana Rumah Sakit Umum Gmim Pancaran Kasih Manado.

Bagi bidang pelayanan keperawatan diharapkan perawat di Paviliun Hana Rumah Sakit Umum GMIM Pancaran Kasih Manado mampu mempertahankan kualitas Caring nya agar kepuasan pasien tetap terjaga. Sebagai tindak lanjut dari hasil studi ini peneliti akan menyarankan kepada Direktur Rumah Sakit Umum GMIM Pancaran Kasih Manado untuk selalu memperhatikan kualitas pelayanan perawat yang berstandar Standard Oprerating Procedure dan berlandaskan pada prinsip Caring Perawat agar kualitas pelayanan keperawatan di Rumah Sakit Umum GMIM Pancaran Kasih Manado tetap baik kualitasnya.

\section{DAFTAR PUSTAKA}

Abdul. (2013). Hubungan Perilaku Caring Perawat dengan Tingkat Kepuasan Pasien Rawat Inap Rumah Sakit. http://journal.unhas.ac.id. Pada Tanggal 8 November 2019.

Azizah, N. (2013). Hubungan Sikap Caring Perawat Dengan Terpenuhinya Hak Pasien Mendapatkan Informasi Tindakan Di Rawat Inap RSU PKU Muhammadiyah Bantul Yogyakarta. Skripsi tidak dipublikasikan. Program Studi Ilmu Keperawatan Sekolah Tinggi Ilmu Kesehatan Aisyiyah. Yogyakarta.

Kalsum. (2016). Hubungan Perilaku Caring Perawat dengan Kepuasan Pasien di Ruang Perawatan Teratai Rumah Sakit Umum Pusat Fatmawati. http://scholar.google.co.id. Pada Tanggal 8 November 2019.

Mailani. (2017). Hubungan Perilaku Caring Perawat dengan Tingkat Kepuasan Pasien BPJS di RSUD DR. Rasidin 
https://www.researchgate.net. Pada Tanggal 8 November 2019.

Paputungan. (2018). Hubungan Caring Perawat dengan Tingkat Kecemasan Pasien Rawat Inap di Rumah Sakit Umum GMIM Pancaran Kasih Manado. hhtps://ejournal.unsrat.ac.id/. Pada tanggal 8 November 2019.

Suweko\&Warsito. (2019). Hubungan Perilaku Caring Perawat Dengan Kepuasan Pasien di Ruang Rawat Inap : Literatur Review. http://ejr.stikesmuhkudus.ac.id. Pada Tanggal 8 November 2019. 